\title{
The Right Superior Frontal Gyrus and Individual Variation in Proactive Control of Impulsive Response
}

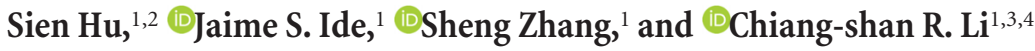 \\ ${ }^{1}$ Department of Psychiatry, Yale University School of Medicine, New Haven, Connecticut 06519, ${ }^{2}$ Department of Psychology, State University of New York \\ at Oswego, Oswego, New York 13126, and ${ }^{3}$ Department of Neuroscience and ${ }^{4}$ Interdepartmental Neuroscience Program, Yale University School of \\ Medicine, New Haven, Connecticut 06520
}

\begin{abstract}
A hallmark of cognitive control is the ability to rein in impulsive responses. Previously, we used a Bayesian model to describe trial-by-trial likelihood of the stop signal or $\mathrm{p}$ (Stop) and related regional activations to $\mathrm{p}$ (Stop) to response slowing in a stop signal task. Here, we characterized the regional processes of conflict anticipation in association with intersubject variation in impulse control in 114 young adults. We computed the stop signal reaction time (SSRT) and a measure of motor urgency, indexed by the reaction time (RT) difference between go and stop error trials or "GoRT - SERT," where GoRT is the go trial RT and SERT is the stop error RT. Motor urgency and SSRT were positively correlated across subjects. A linear regression identified regional activations to $\mathrm{p}$ (Stop), each in correlation with SSRT and motor urgency. We hypothesized that shared neural activities mediate the correlation between motor urgency and SSRT in proactive control of impulsivity. Activation of the ventromedial prefrontal cortex, posterior cingulate cortex and right superior frontal gyrus (SFG) during conflict anticipation correlated negatively with the SSRT. Activation of the right SFG also correlated negatively with GoRT - SERT. Therefore, activation of the right SFG was associated with more efficient response inhibition and less motor urgency. A mediation analysis showed that right SFG activation to conflict anticipation mediates the correlation between SSRT and motor urgency bidirectionally. The current results highlight a specific role of the right SFG in translating conflict anticipation to the control of impulsive response, which is consistent with earlier studies suggesting its function in action restraint.
\end{abstract}

Key words: cognitive control; motor inhibition; neuroimaging; no-go; post-error slowing

\section{Significance Statement}

Individuals vary in impulse control. However, the neural bases underlying individual variation in proactive control of impulsive responses remain unknown. Here, in a large sample of young adults, we showed that activation of the right superior frontal gyrus (SFG) during conflict anticipation is positively correlated with the capacity of inhibitory control and negatively with motor urgency in the stop signal task. Importantly, activity of the right SFG mediates the counteracting processes of inhibitory control and motor urgency across subjects. The results support a unique role of the right SFG in individual variation in cognitive control.

\section{Introduction}

A distinct dimension of cognitive control is the ability to anticipate changes and prepare for behavioral adjustment. In a previous work, we combined computational modeling and fMRI of a stop signal

Received April 6, 2016; revised 0ct. 4, 2016; accepted 0ct. 7, 2016.

Author contributions: S.H., J.S.I., S.Z., and C.R.L. designed research; S.H., J.S.I., S.Z., and C.R.L. performed research; S.H., J.S.I., S.Z., and C.R.L. contributed unpublished reagents/analytic tools; S.H., J.S.I., S.Z., and C.R.L. analyzed data; S.H., J.S.I., S.Z., and C.R.L. wrote the paper.

This work was supported by the National Science Foundation (Grant BCS1309260) and the National Institutes of Health (Grants AA021449 and DA023248). The funding agencies were not involved in data collection or analysis or in the decision to publish the current results. We thank Dr. Angela Yu for many helpful discussions.

The authors declare no competing financial interests.

Correspondence should be addressed to either of the following: Dr. Sien Hu, Department of Psychology, State University of New York at Oswego, 407 Mahar Hall, Oswego, NY 13126, E-mail: sien.hu@oswego.edu; or Dr.C.-S. Ray Li, Connecticut Mental Health Center S112, 34 Park Street, New Haven, CT 06519. E-mail: chiang-shan.li@yale.edu. DOI:10.1523/JNEUROSCI.1175-16.2016

Copyright $\odot 2016$ the authors $\quad 0270-6474 / 16 / 3612688-09 \$ 15.00 / 0$ task to characterize the neural processes linking conflict anticipation, an estimate of the likelihood of an upcoming stop signal or $\mathrm{p}$ (Stop) and go trial reaction time (GoRT). An increase in $\mathrm{p}$ (Stop) predicted a prolonged GoRT. We showed that activity to conflict anticipation in the presupplementary motor area (pre-SMA) Granger caused activity in the posterior pre-SMA, and bilateral anterior insula during go response slowing (Hu et al., 2015). Along with other studies, the latter work characterized the neural circuits for proactive control (Jaffard et al., 2008; Jahfari et al., 2010; Grinband et al., 2011; Criaud et al., 2012; Zandbelt et al., 2013; van Belle et al., 2014; Behan et al., 2015).

Individuals vary in impulsivity, which may conduce to undesirable consequences (Grant and Chamberlain, 2014; Smith et al., 2014). Many clinical conditions implicate dysfunctional impulse control and impulsivity represents a target for behavioral and pharmacological therapy (Friederich et al., 2013; Jahanshahi et 
al., 2015). In the stop signal task, the stop signal reaction time (SSRT), the time required to withhold a motor response successfully in half of the stop trials, captures the capacity of response inhibition (Logan, 1994). By contrasting stop and go trials or stop success and error trials, previous studies have implicated a wide array of cortical and subcortical regions in mediating intersubject variation in the SSRT (Li et al., 2006; Li et al., 2008c; Chao et al., 2009; Duann et al., 2009; Zhang et al., 2015), highlighting a role of reactive control in response inhibition. There is also behavioral evidence that higher stop signal probability or preparation to stop is associated with shorter SSRT (Castro-Meneses et al., 2015; Smittenaar et al., 2015). However, it remains unclear how conflict anticipation may influence the SSRT proactively and how this relationship may vary across individuals.

Earlier work suggests that the SSRT is a product of interaction of the go and stop processes in the stop signal task (Logan et al., 1984; Verbruggen and Logan, 2008). Although studies have largely focused on SSRT as a performance measure of response inhibition, it is known that stop error RT (SERT) is consistently shorter than GoRT, suggesting that motor urgency may contribute to failure in response inhibition (Chikazoe et al., 2009). A greater difference between GoRT and SERT reflects an urgency to respond, the motor aspect of impulsivity. Indeed, a recent study using independent component analysis showed that the activities of motor networks are inversely correlated with SSRT across subjects and that motor urgency, as indexed by the difference in GoRT and SERT or GoRT - SERT and SSRT, are positively correlated across subjects (Zhang et al., 2015). It is thus likely that shared neural substrates mediate the interaction of response inhibition and motor urgency.

Here, in a large cohort of young, healthy adult individuals, we examined the neural processes of conflict anticipation in association with variation in response inhibition (SSRT) and motor urgency (GoRT - SERT) across individuals. Conflict anticipation was quantified by the probability of a stop trial computed from a Bayes optimal decision-making model, which assumes that participants choose whether to "go" on the basis of accumulating evidence. This model explained stopping behavior in the stop signal task and predicted increased stop error rate with increasing stop signal delay as well as faster stop error than correct go response time (Ide et al., 2013; Hu et al., 2015). In combination with the imaging data, we reported that activations of righthemispheric SFG to conflict anticipation are negatively correlated with both SSRT and motor urgency. Mediation analysis showed that right SFG activity fully mediates the correlation between SSRT and GoRT - SERT bidirectionally, suggesting a critical role of the right SFG in linking proactive control to the interactive processes of motor urgency and response inhibition.

\section{Materials and Methods}

Participants, assessments, and behavioral task. One-hundred-and-fourteen adults ( $30.7 \pm 11.0$ years of age, 64 females) participated in this study. We reported differential medial prefrontal cortical responses to conflict anticipation, RT slowing, and unsigned prediction error from the same cohort in a recent study (Hu et al., 2015). All participants were physically healthy with no major medical illnesses or current use of prescription medications. None of them reported having a history of head injury or neurological illness. They signed a written consent after given a detailed explanation of the study in accordance with a protocol approved by the Yale Human Investigation Committee.

All participants performed a stop signal task or SST (Li et al., 2009a; Hendrick et al., 2010; Hu and Li, 2012; Winkler et al., 2013), in which go and stop trials were randomly intermixed in presentation with an intertrial interval of $2 \mathrm{~s}$. A fixation dot appeared on screen to signal the begin- ning of each trial. After an introductory period varying from 1 to $5 \mathrm{~s}$ (uniform distribution), the dot became a circle, the "go" signal, prompting participants to press a button quickly. The circle disappeared at button press or after $1 \mathrm{~s}$ if the participant failed to respond. In approximately one-quarter of trials, the circle was followed by a "cross," the stop signal, prompting participants to withhold button press. The trial terminated at button press or after $1 \mathrm{~s}$ if the participant inhibited the response successfully. The time between the go and stop signals, the stop signal delay (SSD), started at $200 \mathrm{~ms}$ and varied from one stop trial to the next according to a staircase procedure, increasing and decreasing by $67 \mathrm{~ms}$ each after a successful and failed stop trial (Levitt, 1971). With the staircase procedure, we anticipated that participants would succeed in withholding the response half of the time. Participants were trained briefly on the task before imaging to ensure that they understood the task. They were instructed to press the button quickly when they saw the go signal while keeping in mind that a stop signal might come up in some trials ( $\mathrm{Li}$ et al., 2009b). In the scanner, they completed four $10 \mathrm{~min}$ sessions of the task, with $\sim 100$ trials in each session.

Behavioral data analysis. A critical SSD was computed for each participant that represented the time delay required for the participant to withhold the response successfully in half of the stop trials, following a maximum likelihood procedure (Wetheril et al., 1966). Briefly, SSDs across trials were grouped into runs, with each run being defined as a monotonically increasing or decreasing series. We derived a mid-run estimate by taking the middle SSD (or average of the two middle SSDs when there was an even number of SSDs) of every second run. The critical SSD was computed by taking the mean of all mid-run SSDs. It was reported that, except for experiments with a small number of trials $(<30)$, the mid-run measure was close to the maximum likelihood estimate of X50 (50\% positive response; i.e., 50\% SS in the SST; Wetheril et al., 1966). The SSRT was computed for each participant by subtracting the critical SSD from the median go trial reaction time (Logan et al., 1984).

Trial-by-trial Bayesian estimate of the likelihood of a stop signal. As in our previous work (Ide et al., 2013), we used a dynamic Bayesian model (Yu et al., 2009) to estimate the prior belief of an impending stop signal on each trial based on prior stimulus history. The model assumes that subjects believe that stop signal frequency $r_{k}$ on trial $k$ has probability $\alpha$ of being the same as $r_{k-1}$ and probability $(1-\alpha)$ of being resampled from a prior distribution $\pi\left(r_{k}\right)$. Subjects are also assumed to believe that trial $k$ has probability $r_{k}$ of being a stop trial and probability $1-r_{k}$ of being a go trial. With these generative assumptions, subjects are assumed to use Bayesian inference to update their prior belief of seeing a stop signal on trial $k, p\left(r_{k} \mid S_{\mathrm{k}-1}\right)$ based on the prior on the last trial $p\left(r_{k-1} \mid S_{\mathrm{k}-1}\right)$ and the last trial's true category ( $s_{\mathrm{k}}=1$ for stop trial, $s_{\mathrm{k}}=0$ for go trial), where $S_{\mathrm{k}}=\left\{s_{1}, \ldots, s_{\mathrm{k}}\right\}$ is short-hand for all trials 1 through $k$. Specifically, given that the posterior distribution was $p\left(r_{k-1} \mid S_{\mathrm{k}-1}\right)$ on trial $k-1$, the prior distribution of stop signal in trial $k$ is given by the following:

$$
p\left(r_{k} \mid S_{k-1}\right)=\alpha p\left(r_{k-1} \mid S_{k-1}\right)+(1-\alpha) \pi\left(r_{k}\right),
$$

where the prior distribution $\pi\left(r_{k}\right)$ is assumed to be a $\beta$ distribution with prior mean $p m$ and shape parameter scale and the posterior distribution is computed from the prior distribution and the outcome according to the Bayes' rule as follows:

$$
p\left(r_{k} \mid S_{k}\right) \propto P\left(s_{k} \mid r_{k}\right) p\left(r_{k} \mid S_{k-1}\right) .
$$

The Bayesian estimate of the probability of trial $k$ being stop trial, which we colloquially call $\mathrm{p}$ (Stop) herein, given the predictive distribution $p\left(r_{k} \mid S_{\mathrm{k}-1}\right)$, is expressed by the following:

$$
\begin{aligned}
p\left(s_{k}=1 \mid S_{k-1}\right)=\int P\left(s_{k}=1 \mid\right. & \left.r_{k}\right) P\left(r_{k} \mid S_{k-1}\right) d r_{k} \\
& =\int r_{k} P\left(r_{k} \mid S_{k-1}\right) d r_{k}=\left\langle r_{k} \mid S_{k-1}\right\rangle .
\end{aligned}
$$

In other words, the probability $\mathrm{p}$ (Stop) of a trial $k$ being a stop trial is simply the mean of the predictive distribution $p\left(r_{k} \mid S_{\mathrm{k}-1}\right)$. The assump- 
tion that the predictive distribution is a mixture of the previous posterior distributions and a generic prior distribution is essentially equivalent to using a causal, exponential, linear filter to estimate the current rate of stop trials (Yu et al., 2009). In summary, for each subject, given a sequence of observed go/stop trials, and the three model parameters $\{\alpha, p m$, scale $\}$, we estimated $\mathrm{p}$ (Stop) for each trial.

We followed our earlier work in specifying the parameters for Bayesian models (Ide et al., 2013). Specifically, we assumed a prior $\beta$ distribution, $\beta(3.5,7.5)$ equivalent to a prior mean $=0.25$ and scale $=10$ and $\mathrm{a}$ learning parameter $\alpha=0.8$ for all participants. Although each subject might present an optimal set of parameters, as shown in Ide et al. (2013), considering the noisy nature of individual model parameter estimates, we followed the standard of model-based fMRI analyses by keeping a fixed set of parameters across the group to characterize behavior related to stop signal anticipation and regional responses to $\mathrm{p}$ (Stop) (O'Doherty et al., 2004; Daw et al., 2006). Our previous work also showed that the sequential effects, a positive correlation between $\mathrm{p}$ (Stop) and GoRT, are not sensitive to the exact parametrization of the model; a significant correlation between $\mathrm{p}$ (stop) and GoRT is obtained for individual subjects for a wide range of parameters ( $r>0.92$, Pearson regression). The mean of the prior distribution is set at 0.25 to reflect the frequency of stop trials. The validity of the model was confirmed in a more recent work $(\mathrm{Hu}$ et al., 2015).

Imaging protocol and spatial preprocessing of brain images. Conventional T1-weighted spin-echo sagittal anatomical images were acquired for slice localization using a 3T scanner (Siemens Trio). Anatomical images of the functional slice locations were obtained with spin-echo imaging in the axial plan parallel to the anterior commissure-posterior commissure (AC-PC) line with $\mathrm{TR}=300 \mathrm{~ms}, \mathrm{TE}=2.5 \mathrm{~ms}$, bandwidth $=$ $300 \mathrm{~Hz} /$ pixel, flip angle $=60^{\circ}$, field of view $=220 \times 220 \mathrm{~mm}$, matrix $=$ $256 \times 256,32$ slices with slice thickness $=4 \mathrm{~mm}$ and no gap. A single high-resolution T1-weighted gradient-echo scan was obtained. One hundred and seventy-six slices parallel to the AC-PC line covering the whole brain were acquired with $\mathrm{TR}=2530 \mathrm{~ms}$, $\mathrm{TE}=3.66 \mathrm{~ms}$, bandwidth $=181 \mathrm{~Hz} /$ pixel, flip angle $=7^{\circ}$, field of view $=256 \times 256 \mathrm{~mm}$, matrix $=256 \times 256,1 \mathrm{~mm}^{3}$ isotropic voxels. Functional blood oxygenation level-dependent (BOLD) signals were then acquired with a singleshot gradient-echo echo-planar imaging (EPI) sequence. Thirty-two axial slices parallel to the AC-PC line covering the whole brain were acquired with TR $=2000 \mathrm{~ms}, \mathrm{TE}=25 \mathrm{~ms}$, bandwidth $=2004 \mathrm{~Hz} /$ pixel, flip angle $=85^{\circ}$, field of view $=220 \times 220 \mathrm{~mm}$, matrix $=64 \times 64,32$ slices with slice thickness $=4 \mathrm{~mm}$ and no gap. There were 300 images in each session for a total of four sessions.

Data were analyzed with Statistical Parametric Mapping (SPM8, Wellcome Department of Imaging Neuroscience, University College London). In the preprocessing of BOLD data, images of each participant were realigned (motion-corrected) and corrected for slice timing. A mean functional image volume was constructed for each participant for each run from the realigned image volumes. These mean images were coregistered with the high-resolution structural image and then segmented for normalization to a Montreal Neurological Institute (MNI) EPI template with affine registration followed by nonlinear transformation (Friston et al., 1995a; Ashburner and Friston, 1999). Finally, images were smoothed with a Gaussian kernel of $8 \mathrm{~mm}$ at full width at half maximum. Images from the first five TRs at the beginning of each trial were discarded to enable the signal to achieve steady-state equilibrium between radio frequency pulsing and relaxation.

Generalized linear models and group analyses. Our goal was to identify the neural correlates of conflict anticipation or the Bayesian estimate of a stop signal. We distinguished four trial outcomes, go success (GS), go error (GE), stop success (SS), and stop error (SE), and modeled BOLD signals by convolving the onsets of the fixation point (the beginning) of each trial with a canonical hemodynamic response function (HRF) and the temporal derivative of the canonical HRF (Friston et al., 1995b; Hu and $\mathrm{Li}, 2012$ ). Realignment parameters in all six dimensions were entered in the model. We included the following variables as parametric modulators in the model: $\mathrm{p}$ (Stop) of GS trials, SSD of SS trials, $\mathrm{p}$ (Stop) of SS trials, SSD of SE trials, and p(Stop) of SE trials, in that order. Inclusion of these variables as parametric modulators improved model fit (Büchel et al., 1996; Cohen, 1997; Büchel et al., 1998; Hu et al., 2015) and, specifically, the parametric modulator of $\mathrm{p}$ (Stop) allowed us to examine the neural correlates of conflict anticipation. Serial autocorrelation of the time series was corrected by a first degree autoregressive or AR(1) model (Friston et al., 2000; Della-Maggiore et al., 2002). The data were highpass filtered (1/128 Hz cutoff) to remove low-frequency signal drifts. In the first-level analysis, a contrast +1 and -1 on the parametric modulator $\mathrm{p}$ (Stop) of GS trials each examined how positive and negative deviations from the average BOLD amplitude are modulated by trial-by-trial estimate of the likelihood of a stop signal (Wilson et al., 2009; St Jacques et al., 2011). That is, the contrasts identified voxels each with activation increasing and decreasing to $\mathrm{p}$ (Stop).

In the second-level analysis, we reported findings at a voxelwise $p<$ 0.05 corrected for familywise error (FWE) of multiple comparisons or uncorrected threshold of $p<0.001$, along with a cluster threshold of $p<$ 0.05 corrected for FWE. In a one-sample $t$ test, we identified regional activations in positive and negative correlation to $\mathrm{p}$ (Stop). In wholebrain linear regression, we identified regional activations to $\mathrm{p}$ (Stop) each against SSRT and GoRT - SERT.

Mediation analysis. We performed mediation analyses to test the hypothesis that regional activations mediate the association between the SSRT and GoRT - SERT using the toolbox M3 developed by Wager and Lindquist (http://www.columbia.edu/cu/psychology/tor/). The methods were detailed in our previous work (Ide and Li, 2011; Ide et al., 2014). Briefly, in a mediation analysis, the relation between the independent variable $X$ and dependent variable $Y$; that is, $X \rightarrow Y$ is tested to determine whether it is significantly mediated by a variable $M$. The mediation test is performed using the following three regression equations:

$$
\begin{gathered}
\mathrm{Y}=\mathrm{i} 1+c \mathrm{X}+e 1 \\
\mathrm{Y}=\mathrm{i} 2+c^{\prime} \mathrm{X}+b \mathrm{M}+e 2 \\
\mathrm{M}=\mathrm{i} 3+\alpha \mathrm{X}+e 3
\end{gathered}
$$

where $a$ represents $X \rightarrow M, b$ represents $M \rightarrow Y$ (controlling for $X), c^{\prime}$ represents $X \rightarrow Y$ (controlling for $M$ ), and $c$ represents $X \rightarrow Y$. In the literature, $a, b, c$, and $c^{\prime}$ were referred to as "path coefficients" or simply "paths," and we followed this notation. Variable $M$ is said to be a mediator of connection $X \rightarrow Y$, if $\left(c-c^{\prime}\right)$, which is mathematically equivalent to the product of the paths $a \times b$, is significantly different from zero (MacKinnon et al., 2007). If the product of $a \times b$ and the paths $a$ and $b$ are significant, then one concludes that $X \rightarrow Y$ is mediated by $M$. In addition, if path $c^{\prime}$ is not significant, it indicates that there is no direct connection from $X$ to $Y$ and that $X \rightarrow Y$ is completely mediated by $M$. Note that path $b$ represents $M \rightarrow Y$, controlling for $X$, and should not be confused with the correlation coefficient between $Y$ and $M$. Note also that a significant correlation between $X$ and $Y$ and between $X$ and $M$ is required for one to perform the mediation test.

\section{Results}

\section{Behavioral performance}

The median GoRT and SERT were $602 \pm 10 \mathrm{~ms}$ (mean \pm SE) and $533 \pm 9 \mathrm{~ms}$, respectively. Participants responded in $98.6 \pm 0.2 \%$ of go trials and $51.2 \pm 0.3 \%$ of stop trials. The average SSRT was $194 \pm 3 \mathrm{~ms}$ and the difference between the median GoRT and median SERT, or GoRT - SERT, was $69 \pm 30 \mathrm{~ms}$. SSRT and GoRT - SERT were significantly correlated $(r=0.2800, p=$ 0.0025, df $=112$, Pearson regression; Fig. 1).

The Bayesian model predicts that as $\mathrm{p}$ (Stop) increases, GoRT should increase linearly and the stop error rate should decrease linearly. The results for the current cohort showed that, across all participants, GoRT was significantly correlated with p(Stop) $(r=$ $0.9665, p=0.0000, \mathrm{df}=112)$, indicating a strong sequential effect, and the stop error rate was inversely correlated with $\mathrm{p}$ (Stop) $(r=-0.9080, p=0.0000, \mathrm{df}=112)$, both of which were consistent with the predictions of the Bayesian model (see Fig. 1 in Hu et al., 2015). 


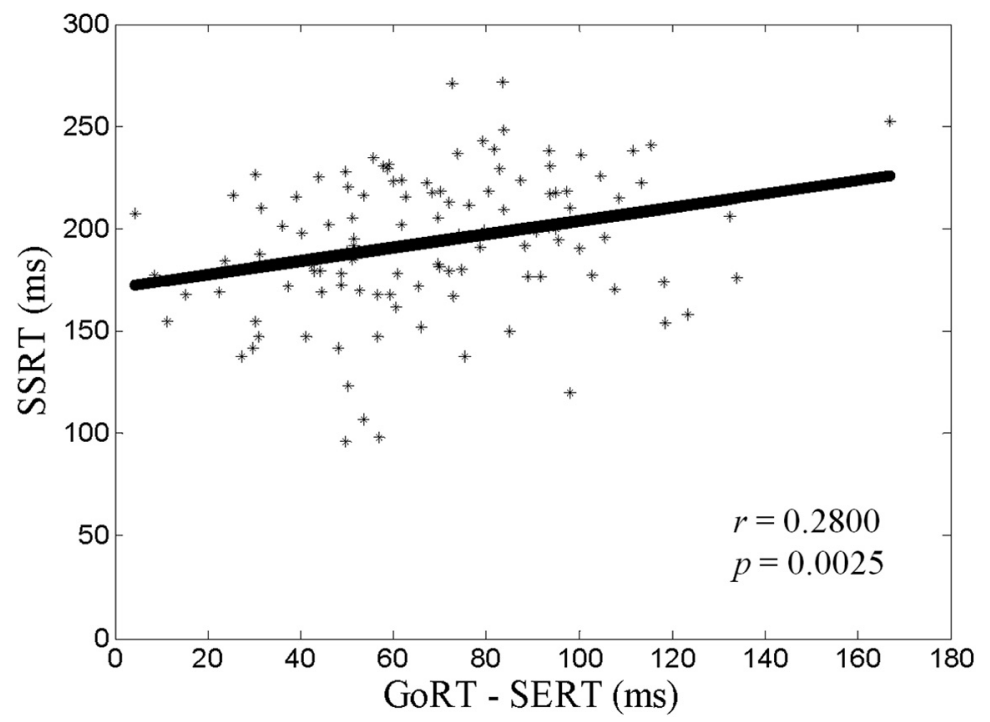

Figure 1. Correlation between SSRT and GORT - SERT. Each data point represents one participant. The line indicates the fit by Pearson regression.

\section{Regional activations to stop signal anticipation: parametric modulation by $\mathbf{p}$ (Stop)}

The results showed positive modulation by $\mathrm{p}$ (Stop) in bilateral inferior parietal lobules, right middle frontal cortex, orbitofrontal cortex, middle cingulate cortex, anterior pre-SMA, left cerebellum, and right insula (Fig. 2, Table 1). Regions with negative responses to $\mathrm{p}$ (Stop) are found in the ventromedial prefrontal cortex (vmPFC), left caudate head, bilateral primary motor cortices, parahippocampal gyrus, posterior cingulate cortices and middle occipital cortices, as well as left SFG (Fig. 2, Table 1).

\section{Regional responses to $\mathrm{p}($ Stop) in correlation with SSRT and GoRT - SERT}

A linear regression of responses to $\mathrm{p}$ (Stop) against SSRT showed negative correlations in the $\operatorname{vmPFC}(x=0, y=35, z=1, k=$ $1122, Z=5.34)$, right SFG $(x=21, y=35, z=46, k=99, Z=$ $4.09)$, and posterior cingulate cortex $(x=3, y=-49, z=25$, $k=100, Z=3.82$ ) (Fig. $3 b$ ). A linear regression of responses to $\mathrm{p}$ (Stop) against GoRT - SERT showed negative correlations in the right SFG $(x=21, y=29, z=34, k=162, Z=4.04)$ (Fig. $3 c$ ). No brain regions showed positive correlations in either regression at the same threshold. Further, to determine whether GoRT may be a significant confounder, we included GoRT as an additional regressor in the latter general linear model (GLM). The results identified the same right SFG cluster $(x=21, y=29, z=$ $\left.34, k=144, Z=4.10, p_{\mathrm{FWE}}=0.008\right)$ in negative association with motor urgency (GoRT - SERT).

\section{Right SFG response to $\mathrm{p}$ (Stop) mediates correlation of SSRT and GoRT - SERT bidirectionally}

As shown in Figure 3, $b$ and $c$, the right SFG responses to $\mathrm{p}$ (Stop) were negatively correlated with both SSRT and GoRT - SERT. That is, the right SFG represents a shared neural correlate for efficient response inhibition and less motor urgency. We identified a cluster of the right SFG that overlapped in the correlation with SSRT and GoRT - SERT. We hypothesized that activity of the right SFG (Fig. 4a) mediate the correlation between SSRT and GoRT - SERT (Figs. 1, 4b). In mediation analysis, we tested the specificity of this relationship by examining all six mediation models. In the first model, the SSRT served as the independent

\section{Discussion}

variable $X$, GoRT - SERT as the dependent variable $Y$, and the contrast value of SFG activity as the mediating variable $M$. In the second model, GoRT - SERT served as $X$, SSRT as $Y$, and SFG activity as $M$. In the third model, SFG activity served as $X$, the SSRT as $Y$, and GoRT - SERT as $M$. In the fourth model, SFG activity served as $X$, GoRT - SERT as $Y$, and SSRT as $M$. We did not consider the other two models in which voxel activity served as the dependent variable because, as a neural phenotype, voxel activity causes behavioral manifestations, but the reverse is not true. However, these two models were included for completeness.

The results showed that the right SFG exclusively mediated the relationship between SSRT and GoRT - SERT bidirectionally (Fig. $4 c$, Table 2). That is, the correlation between SSRT and right SFG and that between GoRT - SERT and SFG were both significant and the correlation between SSRT and GoRT - SERT was fully accounted for by SFG activity (see Materials and Methods). Conversely, neither GoRT - SERT or SSRT significantly mediated the correlation between SFG activity and the other variable (Table 2). In the remaining two models, there were no significant mediation effects.

Neural correlates of individual variation in impulse control Although studies have combined brain imaging and various behavioral measures to characterize the neural processes of impulse control, few have focused on how these processes account for individual variation in impulsivity in nonclinical populations. In the realm of cognitive motor control, for instance, urgency as a dimensional index of impulsivity trait is associated with prolonged SSRT in the SST and negatively correlated with activation of the right inferior frontal cortex and anterior insula during stop versus go trials (Wilbertz et al., 2014). Our earlier work showed that Barratt impulsivity is associated with decreased activation and connectivity in the right middle frontal cortex and anterior insula during stop versus go trials, but is only marginally correlated with the SSRT (Farr et al., 2012). These studies highlighted a potential relationship between individual variation in impulsivity and frontal cortical processes of saliency response and reactive control.

On the other hand, it remains unclear whether or how proactive control mediates individual variation in impulsivity. Here, building on our earlier studies, we characterized whole-brain activations to conflict anticipation and regional processes that relate conflict anticipation to two measures of impulse control: response inhibition, as indexed by the SSRT, and motor urgency, as indexed by GoRT - SERT. The results showed that right SFG activity is associated with both efficient response inhibition and less motor urgency. In addition, the right SFG fully mediates the correlation between response inhibition and motor urgency, suggesting its critical role in dictating the interaction between countermanding decisions to go and stop in the SST.

The right SFG has been implicated in inhibitory control, particularly when driven by a "top-down" process. In a marble task, the right SFG $(x=21, y=33, z=54$, within the cluster identified 


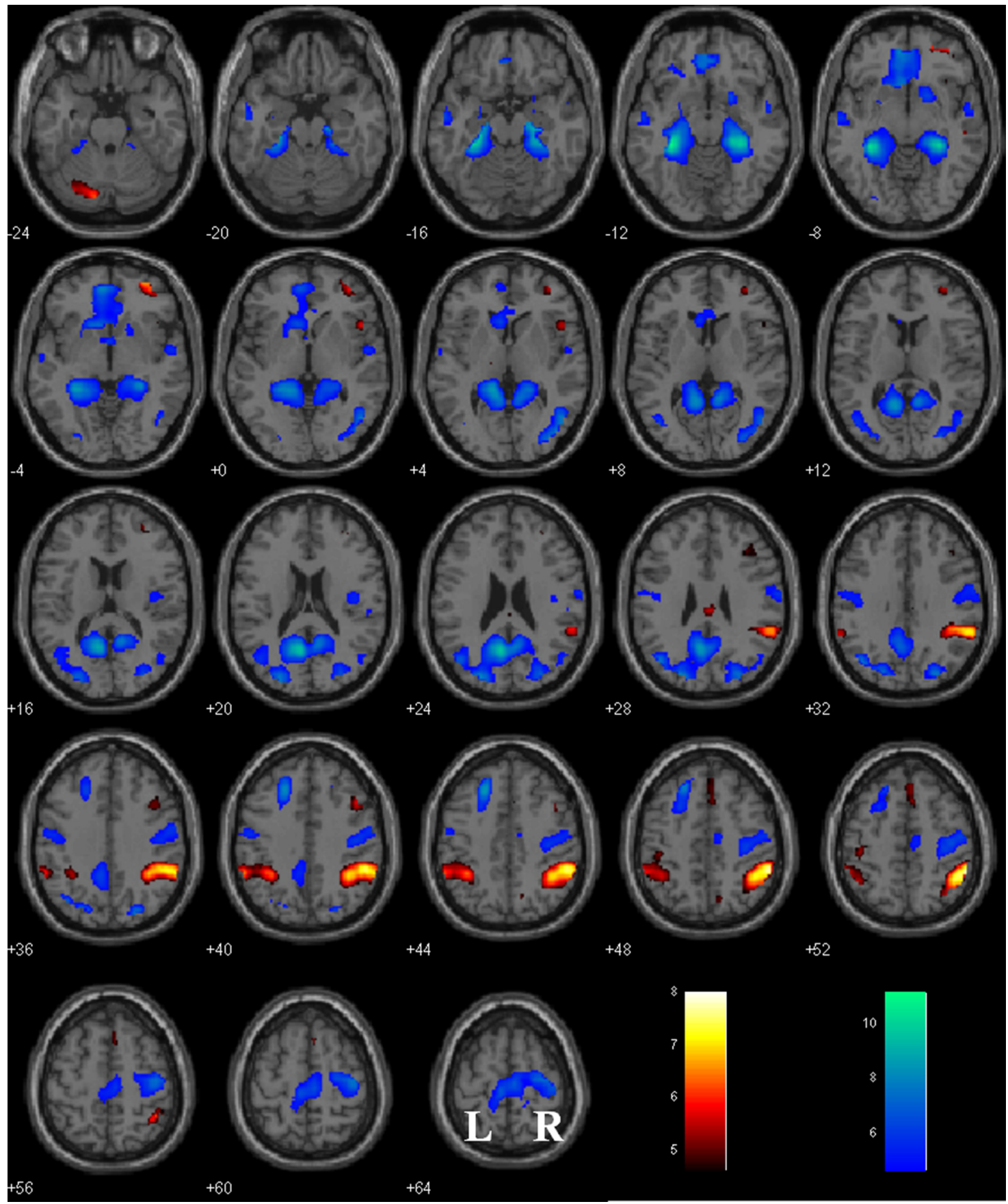

Figure 2. Regional activations as modulated by $p($ Stop) overlaid on a T1 structural image in axial sections ( $p<0.05$ FWE). Warm colors indicate positive modulation; cool colors, negative modulation. Color bar indicates $T$ value. Neurological orientation: $r=$ right.

here: $x=21, y=35, z=46)$ showed greater activation during intentional inhibition versus intentional action (Schel et al., 2014). The right SFG is part of a cortical network that responds specifically to action restraint in go/no-go task (Dambacher et al., 2014b). Disruption of the right SFG by continuous theta-burst stimulation specifically impaired the ability to refrain from responding in a go/no-go task while leaving the ability for action cancellation in the SST largely intact (Dambacher et al., 2014a). These two studies suggest a specific role of the right SFG in proactive control of impulsive responses.

A recent study described in detail the anatomical and functional connectivity of the SFG (Li et al., 2013). With diffusion tensor tractography, the investigators parcellated the SFG into anteromedial (SFGam), dorsolateral (SFGdl), and posterior (SFGp) subregions. In the analysis of resting-state functional connectivity, the right SFGdl is positively connected to the anterior and posterior cingulate cortices, middle frontal gyrus, caudate, and thalamus but negatively connected to the inferior frontal and precentral gyri in an exactly opposite pattern to right SFGp. The current finding of right SFG cluster corresponds in location to an anterior part of the SFGdl, in the anterior lateral portion of the Brodmann area 9. This anterior subregion of the SFGdl is more strongly connected to the default mode network compared with the posterior subregion. An earlier study of graph theoretical measures suggested that stronger connectivities between the SFG and posterior cingulate cortex are associated with 
Table 1. Regional activations modulated by $\mathrm{p}$ (Stop) with whole-brain evaluation at $p<0.05$ FWE

\begin{tabular}{|c|c|c|c|c|c|c|}
\hline \multirow[b]{2}{*}{ Region } & \multirow{2}{*}{$\begin{array}{l}\text { Cluster size } \\
\text { (\#voxels) }\end{array}$} & \multirow{2}{*}{$\begin{array}{l}\text { Cluster FWE } \\
p \text {-value }\end{array}$} & \multirow{2}{*}{$\begin{array}{l}\text { Peak voxel } \\
\text { Z-value }\end{array}$} & \multicolumn{3}{|c|}{$\begin{array}{l}\text { MNI coordinates } \\
(\mathrm{mm})\end{array}$} \\
\hline & & & & $\bar{x}$ & $\bar{Y}$ & $Z$ \\
\hline \multicolumn{7}{|l|}{ Positive modulation by $\mathrm{p}$ (Stop) } \\
\hline R inferior parietal lobule & 547 & 0.000 & 7.11 & 57 & -43 & 49 \\
\hline L cerebellum & 107 & 0.000 & 6.40 & -24 & -70 & -32 \\
\hline R orbital frontal cortex & 137 & 0.000 & 6.26 & 33 & 56 & -5 \\
\hline L inferior parietal lobule & 285 & 0.000 & 6.11 & -57 & -46 & 40 \\
\hline R middle frontal cortex & 43 & 0.000 & 5.48 & 45 & 17 & 43 \\
\hline Rinsula & 30 & 0.000 & 5.45 & 48 & 17 & 1 \\
\hline R/L midcingulate cortex & 20 & 0.001 & 5.38 & 3 & -25 & 28 \\
\hline R/L anterior pre-SMA & 73 & 0.000 & 5.04 & 3 & 20 & 49 \\
\hline \multicolumn{7}{|l|}{ Negative modulation by $p($ Stop) } \\
\hline L parahippocampal gyrus & 3621 & 0.000 & INF & -33 & -37 & -11 \\
\hline R parahippocampal gyrus & & 0.000 & INF & 33 & -31 & -14 \\
\hline R/L posterior cingulate cortex & & 0.000 & INF & -6 & -61 & 22 \\
\hline L middle occipital cortex & & 0.000 & 7.27 & -24 & -85 & 25 \\
\hline $\mathrm{R} / \mathrm{L}$ ventromedial PFC & & 0.000 & 7.15 & -6 & 50 & -5 \\
\hline L superior frontal gyrus & 222 & 0.000 & 7.67 & -21 & 29 & 43 \\
\hline R PMC and R/L PCL & 928 & 0.000 & 6.86 & 42 & -19 & 58 \\
\hline L inferior temporal gyrus & 73 & 0.000 & 6.19 & -57 & -7 & -17 \\
\hline R inferior temporal gyrus & 62 & 0.000 & 5.87 & 57 & -4 & -14 \\
\hline LPMC & 107 & 0.000 & 5.58 & -51 & -10 & 40 \\
\hline
\end{tabular}

All peak voxels $8 \mathrm{~mm}$ apart are identified.

PCL, Paracentral lobule; PMC, primary motor cortex.

better interference control during healthy aging (Wen et al., 2011). Although the literature on the functional significance of SFG connectivity is limited, these findings suggest the importance of distinguishing SFG subregions in imaging studies.

A broader role of the superior frontal gyrus in executive functions in health and illness

The literature specifically on the SFG is somewhat scanty. However, structural and functional imaging studies have provided evidence supporting a broader role of the SFG in executive func- tions in both healthy individuals and those with neuropsychiatric conditions. Reduced cortical thickness of bilateral SFG is associated with inattentional impulsivity, as assessed by the Barratt Impulsivity Scale, in healthy young adults (Schilling et al., 2012). Reduced cortical thickness specifically of the right SFG is reported in patients with attention deficit hyperactivity disorder (Almeida et al., 2010). Repetitive transcranial magnetic stimulation of the SFG modulates craving in cigarette smokers (Rose et al., 2011). Altered cortical thickness and functional connectivity of the right prefrontal cortex including the SFG is associated with impulsive responses in individuals with posttraumatic stress disorders (Sadeh et al., 2015). The clinical efficacy of deep brain electrical stimulation of the subthalamic nucleus (STN) in reducing parkinsonian symptoms, including cognitive motor control, is associated with STN connectivity to the thalamus and, in particular, to the SFG (Vanegas-Arroyave et al., 2016). Deficits in executive functioning in patients with amyotrophic lateral sclerosis are associated with impaired white matter integrity of the SFG (Pettit et al., 2013). In patients with traumatic brain injury, although the decline in fractional anisotropy of the white matter is widespread, the changes in the pre-SMA and SFG are particularly associated with impairment in task switching (Leunissen et al., 2014). While tangential to the current findings, these earlier studies suggest the importance of unraveling the full spectrum of SFG function in both basic and clinical research.

\section{Implications for individual difference research}

Individual difference has drawn increasing attention in systems and cognitive neuroscience research. This research provides evidence to support the variability in cognitive performance and its neural bases in the population. It also suggests that regional brain processes that do not manifest in the population means may nevertheless reflect variance of the mean that is of individual significance. Here, whereas the mean signal does not differ significantly from zero (Fig. 4b), activation of the right SFG to conflict anticipation supports individual variation in impulse

a Regional activations to $\mathrm{p}$ (Stop)

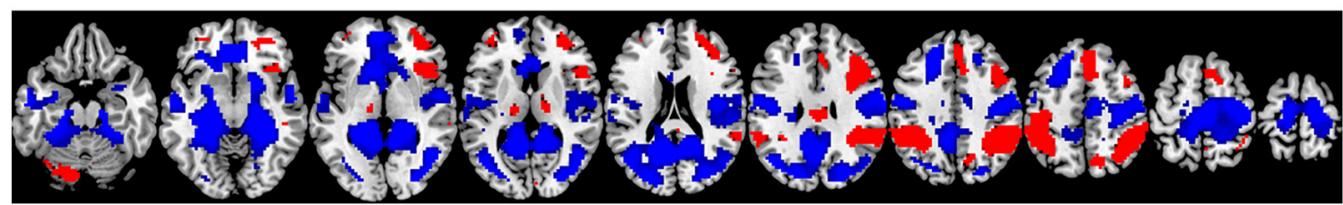

b $\mathrm{p}$ (Stop) regression with SSRT

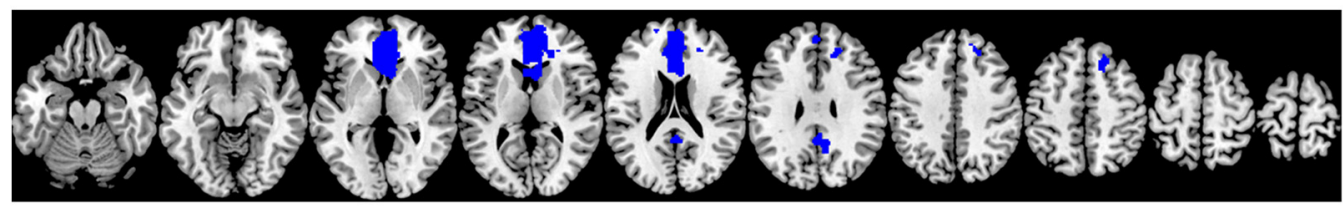

c $\mathrm{p}$ (Stop) regression with GoRT-SERT

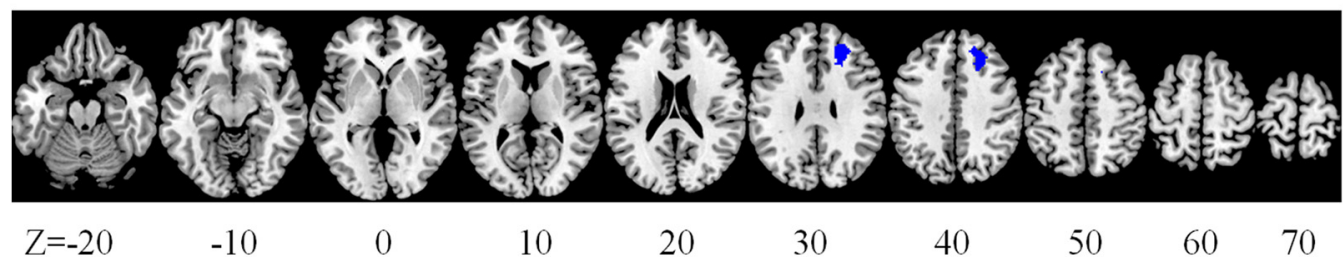

Figure 3. Regional responses to conflict anticipation in association with SSRT and motor urgency. $\boldsymbol{a}$, Whole-brain responses to $\mathrm{p}$ (Stop) shown at the same axial sections for comparison. $\boldsymbol{b}$, Regional responses to $\mathrm{p}(\mathrm{Stop})$ in positive and negative correlation with SSRT (b) and GoRT - SERT (c). Clusters with negative correlation are shown in blue. No clusters showed positive correlation. 
a

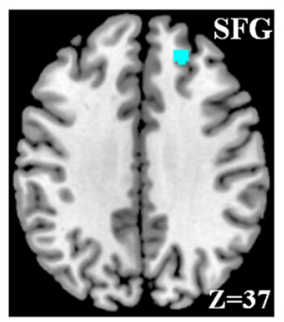

C

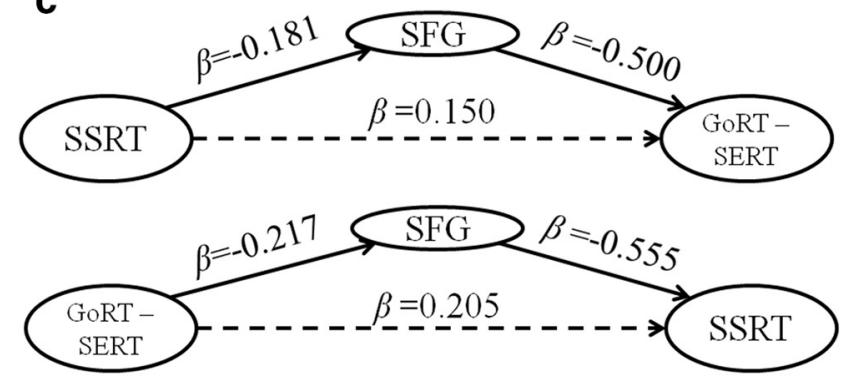

b
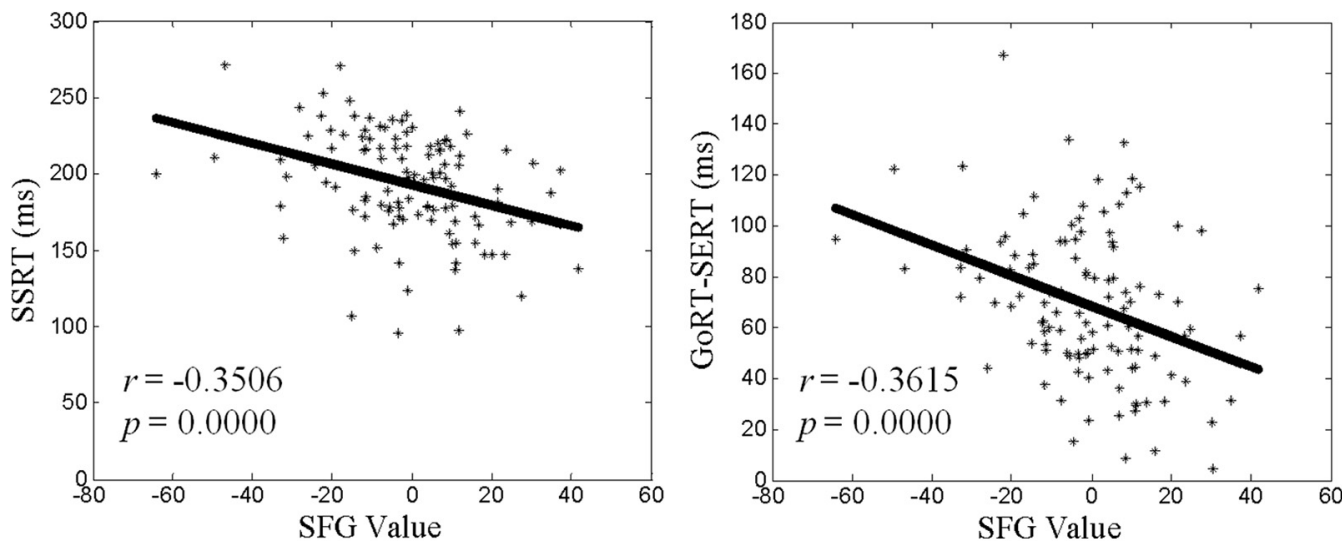

Figure 4. $\quad \boldsymbol{a}$, A cluster in the right SFG with responses to $\mathrm{p}$ (Stop) that correlate linearly with both SSRT and GoRT - SERT. $\boldsymbol{b}$, SFG activity (contrast value) is linearly correlated with both SSRT and GORT - SERT. c, Mediation analysis showing that SFG activity mediates the correlation between SSRT and GoRT - SERT bidirectionally.

Table 2. Mediation of SSRT, GORT - SERT, and activity in the right SFG

\begin{tabular}{|c|c|c|c|c|}
\hline & Path $a(X \rightarrow M)$ & Path $b(M \rightarrow \eta)$ & Path $c^{\prime}(X \rightarrow \eta)$ & Mediation path $a * b$ \\
\hline \multicolumn{5}{|c|}{ MODEL 1:X(SSRT) $\rightarrow Y$ (GoRT - SERT) mediated by $M($ SFG) } \\
\hline$\beta$ & -0.181 & -0.500 & 0.150 & 0.091 \\
\hline$p$-values & $0.000^{*}$ & $0.002^{*}$ & 0.063 & $0.014^{*}$ \\
\hline \multicolumn{5}{|c|}{ MODEL 2: X (GoRT - SERT) $\rightarrow Y$ (SSRT) mediated by $M$ (SFG) } \\
\hline$\beta$ & -0.217 & -0.555 & 0.205 & 0.121 \\
\hline$p$-values & $0.000^{*}$ & $0.003^{*}$ & 0.063 & $0.016^{*}$ \\
\hline \multicolumn{5}{|c|}{ MODEL 3:X(SFG) $\rightarrow Y$ (SSRT) mediated by $M$ (GoRT - SERT) } \\
\hline$\beta$ & -0.602 & 0.205 & -0.555 & -0.123 \\
\hline$p$-values & $0.000^{*}$ & 0.063 & $0.003^{*}$ & 0.090 \\
\hline \multicolumn{5}{|c|}{ MODEL 4:X(SFG) $\rightarrow Y(G O R T$ - SERT) mediated by $M$ (SSRT) } \\
\hline$\beta$ & -0.678 & 0.150 & -0.500 & -0.102 \\
\hline$p$-values & $0.000^{*}$ & 0.063 & $0.002^{*}$ & 0.092 \\
\hline \multicolumn{5}{|c|}{ MODEL 5: $X($ SSRT) $\rightarrow Y$ (SFG) mediated by $M$ (GoRT - SERT) } \\
\hline$\beta$ & 0.241 & -0.172 & -0.140 & -0.041 \\
\hline$p$-values & $0.003^{*}$ & $0.002^{*}$ & $0.003^{*}$ & $0.028^{*}$ \\
\hline \multicolumn{5}{|c|}{ MODEL 6:X(GoRT - SERT) $\rightarrow Y(\mathrm{SFG})$ mediated by $M($ SSRT) } \\
\hline$\beta$ & 0.325 & -0.140 & -0.172 & -0.046 \\
\hline$p$-values & $0.003^{*}$ & $0.003^{*}$ & $0.002^{*}$ & $0.032^{*}$ \\
\hline
\end{tabular}

$\beta$, Regression coefficient.

${ }^{*}$ Significant at $p<0.05$. If paths $a$ and $b$ and their product are significant and path $c^{\prime}$ is not significant, then one concludes that $X \rightarrow Y$ is completely mediated by $M$.

control. Our earlier study of post-error slowing, the slowing of GoRT after a stop error, provides another example to illustrate this issue (Ide and Li, 2011). We identified activations of multiple cortical regions, including the dorsal anterior cingulate cortex and inferior parietal cortex, to error detection and activations of the ventrolateral PFC (vlPFC) to post-error slowing (Li et al., 2008a, 2008b). However, these regional responses were not correlated across subjects, raising questions about the behavioral validity of the imaging findings. To address this issue, we used Granger causality mapping and identified error-related activities of an anatomically known cortico-pontine-cerebellar-thalamic network in correlation with vlPFC responses during post-error slowing (Ide and Li, 2011). Importantly, the mean values of error responses for many of these regions in the circuit were not significantly different from zero, again suggesting that the neural processes in support of individual variation eluded GLM analyses focusing on population means.

Other model-based approaches also provided evidence in support of individual variation in motor execution and inhibition (Hu et al., 2014; White et al., 2014). In White et al. (2014), the investigators used a diffusion model to characterize stimulus information processing and its relationship to stop signal task performance. Faster go stimulus processing, as indexed by the drift rate, was negatively correlated with go mean RT and SSRT as well as greater activation of inhibition-related regions such as the right inferior frontal cortex during successful inhibitions versus go trials. These findings appear to be in contrast to the current results because a faster go response would presumably involve expedition of the motor process and lead to compromised inhibition. However, faster go stimulus processing was associated with greater right frontal pole activation for both go and stop trials, suggesting that the drift rate likely captured an executive process that broadly contributes to both go and stop response. In support, mean GoRT and SSRT were strongly correlated across subjects in this study. Therefore, the diffusion model identified key process parameters that help in the interpretation of behavioral and imaging findings. In the current work, we examined individual variation in impulsivity from the perspective of proactive control, which manifests through an interaction of conflict anticipation, response inhibition, and motor urgency. Future work to combine these computational models in the same dataset would allow investigators to test many hypotheses, including whether individual variation in the strength of sequential effect is related to an elevated decision threshold in motor response. 


\section{Limitations and conclusions}

As a potential limitation of the study, path $c^{\prime}$ of Model 1 and 2 of the mediation analyses is at trend level significance $(p=0.063)$, suggesting that other regional activities may also play a role in mediating the bidirectional relationship between SSRT and GoRT - SERT. More studies are warranted to examine the neural processes underlying the role of proactive control in determining intersubject variation in impulsivity.

To conclude, we showed that right superior frontal cortical activations to conflict anticipation are related to intersubject variation in impulse control, as assessed by the stop signal task. Greater modulation by the likelihood of a stop signal in the right SFG is correlated with more efficient response inhibition and less motor urgency. Further, activity of the right SFG fully mediates the relationship between response inhibition and motor urgency, in support of a neural phenotype of proactive control of impulsivity.

\section{References}

Almeida LG, Ricardo-Garcell J, Prado H, Barajas L, Fernández-Bouzas A, Avila D, Martínez RB (2010) Reduced right frontal cortical thickness in children, adolescents and adults with ADHD and its correlation to clinical variables: a cross-sectional study. J Psychiatr Res 44:1214-1223. CrossRef Medline

Ashburner J, Friston KJ (1999) Nonlinear spatial normalization using basis functions. Hum Brain Mapp 7:254-266. Medline

Behan B, Stone A, Garavan H (2015) Right prefrontal and ventral striatum interactions underlying impulsive choice and impulsive responding. Hum Brain Mapp 36:187-198. CrossRef Medline

Büchel C, Wise RJ, Mummery CJ, Poline JB, Friston KJ (1996) Nonlinear regression in parametric activation studies. Neuroimage 4:60-66. CrossRef Medline

Büchel C, Holmes AP, Rees G, Friston KJ (1998) Characterizing stimulusresponse functions using nonlinear regressors in parametric fMRI experiments. Neuroimage 8:140-148. CrossRef Medline

Castro-Meneses LJ, Johnson BW, Sowman PF (2015) The effects of impulsivity and proactive inhibition on reactive inhibition and the go process: insights from vocal and manual stop signal tasks. Front Hum Neurosci 9:529. CrossRef Medline

Chao HH, Luo X, Chang JL, Li CS (2009) Activation of the presupplementary motor area but not inferior prefrontal cortex in association with short stop signal reaction time: an intra-subject analysis. BMC Neurosci 10:75. CrossRef Medline

Chikazoe J, Jimura K, Hirose S, Yamashita K, Miyashita Y, Konishi S (2009) Preparation to inhibit a response complements response inhibition during performance of a stop-signal task. J Neurosci 29:15870-15877. CrossRef Medline

Cohen MS (1997) Parametric analysis of fMRI data using linear systems methods. Neuroimage 6:93-103. CrossRef Medline

Criaud M, Wardak C, Ben Hamed S, Ballanger B, Boulinguez P (2012) Proactive inhibitory control of response as the default state of executive control. Front Psychol 3:59. CrossRef Medline

Dambacher F, Sack AT, Lobbestael J, Arntz A, Brugmann S, Schuhmann T (2014a) The role of right prefrontal and medial cortex in response inhibition: Interfering with action restraint and action cancellation using transcranial magnetic brain stimulation. J Cogn Neurosci 26:1775-1784. CrossRef Medline

Dambacher F, Sack AT, Lobbestael J, Arntz A, Brugman S, Schuhmann T (2014b) A network approach to response inhibition: dissociating functional connectivity of neural components involved in action restraint and action cancellation. Eur J Neurosci 39:821-831. CrossRef Medline

Daw ND, O'Doherty JP, Dayan P, Seymour B, Dolan RJ (2006) Cortical substrates for exploratory decisions in humans. Nature 441:876-879. CrossRef Medline

Della-Maggiore V, Chau W, Peres-Neto PR, McIntosh AR (2002) An empirical comparison of SPM preprocessing parameters to the analysis of fMRI data. Neuroimage 17:19-28. CrossRef Medline

Duann JR, Ide JS, Luo X, Li CS (2009) Functional connectivity delineates distinct roles of the inferior frontal cortex and presupplementary motor area in stop signal jnhibition. J Neurosci 29:10171-10179. CrossRef Medline
Farr OM, Hu S, Zhang S, Li CS (2012) Decreased saliency processing as a neural measure of Barratt impulsivity in healthy adults. Neuroimage 63: 1070-1077. CrossRef Medline

Friederich HC, Wu M, Simon JJ, Herzog W (2013) Neurocircuit function in eating disorders. Int J Eat Disord 46:425-432. CrossRef Medline

Friston KJ, Ashburner J, Frith CD, Poline JB, Heather JD, Frackowiak RSJ (1995b) Spatial registration and normalization of images. Hum Brain Mapp 2:165-189. CrossRef

Friston KJ, Josephs O, Zarahn E, Holmes AP, Rouquette S, Poline J (2000) To smooth or not to smooth? Bias and efficiency in fMRI time-series analysis. Neuroimage 12:196-208. CrossRef Medline

Friston K, Holmes AP, Worsley KJ, Poline JB, Frith CD, Frackowiak R (1995a) Statistical parametric maps in functional imaging: a general linear approach. Hum Brain Mapp 2:189-210.

Grant JE, Chamberlain SR (2014) Impulsive action and impulsive choice across substance and behavioral addictions: cause or consequence? Addict Behav 39:1632-1639. CrossRef Medline

Grinband J, Savitskaya J, Wager TD, Teichert T, Ferrera VP, Hirsch J (2011) The dorsal medial frontal cortex is sensitive to time on task, not response conflict or error likelihood. Neuroimage 57:303-311. CrossRef Medline

Hendrick OM, Ide JS, Luo X, Li CS (2010) Dissociable processes of cognitive control during error and non-error conflicts: a study of the stop signal task. PLoS One 5:e13155. CrossRef Medline

Hu S, Li CS (2012) Neural processes of preparatory control for stop signal inhibition. Hum Brain Mapp 33:2785-2796. CrossRef Medline

Hu S, Tseng YC, Winkler AD, Li CS (2014) Neural bases of individual variation in decision time. Hum Brain Mapp 35:2531-2542. CrossRef Medline

Hu S, Ide JS, Zhang S, Li CS (2015) Anticipating conflict: Neural correlates of a Bayesia belief and its motor consequence. Neuroimage 119:286-295. CrossRef Medline

Ide JS, Li CS (2011) A cerebellar thalamic cortical circuit for error-related cognitive control. Neuroimage 54:455-464. CrossRef Medline

Ide JS, Shenoy P, Yu AJ, Li CS (2013) Bayesian prediction and evaluation in the anterior cingulate cortex. J Neurosci 33:2039-2047. CrossRef Medline

Ide JS, Zhang S, Hu S, Matuskey D, Bednarski SR, Erdman E, Farr OM, Li CS (2014) Gray matter volume correlates of global positive alcohol expectancy in non-dependent adult drinkers. Addict Biol 19:895-906. CrossRef Medline

Jaffard M, Longcamp M, Velay JL, Anton JL, Roth M, Nazarian B, Boulinguez P (2008) Proactive inhibitory control of movement assessed by eventrelated fMRI. Neuroimage 42:1196-1206. CrossRef Medline

Jahanshahi M, Obeso I, Baunez C, Alegre M, Krack P (2015) Parkinson's disease, the subthalamic nucleus, inhibition, and impulsivity. Mov Disord 30:128-140. CrossRef Medline

Jahfari S, Stinear CM, Claffey M, Verbruggen F, Aron AR (2010) Responding with restraint: what are the neurocognitive mechanisms? J Cogn Neurosci 22:1479-1492. CrossRef Medline

Leunissen I, Coxon JP, Caeyenberghs K, Michiels K, Sunaert S, Swinnen SP (2014) Task switching in traumatic brain injury relates to cortico-subcortical integrity. Hum Brain Mapp 35:2459-2469. CrossRef Medline

Levitt H (1971) Transformed up-down methods in psychoacoustics. J Acoust Soc Am 49:467-477. CrossRef

Li CS, Huang C, Constable RT, Sinha R (2006) Imaging response inhibition in a stop-signal task: neural correlates independent of signal monitoring and post-response processing. J Neurosci 26:186-192. CrossRef Medline

Li CS, Huang C, Yan P, Paliwal P, Constable RT, Sinha R (2008a) Neural correlates of post-error slowing during a stop signal task: A functional magnetic resonance imaging study. J Cogn Neurosci 20:1021-1029. CrossRef Medline

Li CS, Yan P, Chao HH, Sinha R, Paliwal P, Constable RT, Zhang S, Lee TW (2008b) Error-specific medial cortical and subcortical activity during the stop signal task: A functional magnetic resonance imaging study. Neuroscience 155:1142-1151. CrossRef Medline

Li CS, Yan P, Sinha R, Lee TW (2008c) Subcortical processes of motor response inhibition during a stop signal task. Neuroimage 41:1352-1363. CrossRef Medline

Li CS, Chao HH, Lee TW (2009a) Neural correlates of speeded as compared with delayed responses in a stop signal task: an indirect analog of risk taking and association with an anxiety trait. Cereb Cortex 19:839-848. CrossRef Medline

Li CS, Zhang S, Duann JR, Yan P, Sinha R, Mazure CM (2009b) Gender 
differences in cognitive control: an extended investigation of the stop signal task. Brain Imaging Behav 3:262-276. CrossRef Medline

Li W, Qin W, Liu H, Fan L, Wang J, Jiang T, Yu C (2013) Subregions of the human superior frontal gyrus and their connections. Neuroimage 78:4658. CrossRef Medline

Logan GD (1994) On the ability to inhibit thought and action. In: Inhibitory processes in attention, memory and language (Dagenbach D, Carr TH, eds), pp 189-239. San Diego: Academic.

Logan GD, Cowan WB, Davis KA (1984) On the ability to inhibit simple and choice reaction-time responses: a model and a method. J Exp Psychol Hum Percept Perform 10:276-291. CrossRef Medline

MacKinnon DP, Fairchild AJ, Fritz MS (2007) Mediation analysis. Annu Rev Psychol 58:593-614. CrossRef Medline

O’Doherty J, Dayan P, Schultz J, Deichmann R, Friston K, Dolan RJ (2004) Dissociable roles of ventral and dorsal striatum in instrumental conditioning. Science 304:452-454. CrossRef Medline

Pettit LD, Bastin ME, Smith C, Bak TH, Gillingwater TH, Abrahams S (2013) Executive deficits, not processing speed relates to abnormalities in distinct prefrontal tracts in amyotrophic lateral sclerosis. Brain 136:3290-3304. CrossRef Medline

Rose JE, McClernon FJ, Froeliger B, Behm FM, Preud'homme X, Krystal AD (2011) Repetitive transcranial magnetic stimulation of the superior frontal gyrus modulates craving for cigarettes. Biol Psychiat 70:794-799. CrossRef Medline

Sadeh N, Spielberg JM, Miller MW, Milberg WP, Salat DH, Amick MM, Fortier CB, McGlinchey RE (2015) Neurobiological indicators of disinhibition in posttraumatic stress disorder. Hum Brain Mapp 36:30763086. CrossRef Medline

Schel MA, Kühn S, Brass M, Haggard P, Ridderinkhof KR, Crone EA (2014) Neural correlates of intentional and stimulus-driven inhibition: a comparison. Front Hum Neurosci 8:27. CrossRef Medline

Schilling C, Kühn S, Romanowski A, Schubert F, Kathmann N, Gallinat J (2012) Cortical thickness correlates with impulsiveness in healthy adults. Neuroimage 59:824-830. CrossRef Medline

Smith JL, Mattick RP, Jamadar SD, Iredale JM (2014) Deficits in behavioural inhibition in substance abuse and addiction: a meta-analysis. Drug Alcohol Depend 145:1-33. CrossRef Medline

Smittenaar P, Rutledge RB, Zeidman P, Adams RA, Brown H, Lewis G, Dolan RJ (2015) Proactive and reactive response inhibition across the lifespan. PLoS One 10.

St Jacques PL, Botzung A, Miles A, Rubin DC (2011) Functional neuroimaging of emotionally intense autobiographical memories in posttraumatic stress disorder. J Psychiatr Res 45:630-637. CrossRef Medline van Belle J, Vink M, Durston S, Zandbelt BB (2014) Common and unique neural networks for proactive and reactive response inhibition revealed by independent component analysis of functional MRI data. Neuroimage 103:65-74. CrossRef Medline

Vanegas-Arroyave N, Lauro PM, Huang L, Hallett M, Horovitz SG, Zaghloul KA, Lungu C (2016) Tractography patterns of subthalamic nucleus deep brain stimulation. Brain 139:1200-1210. CrossRef Medline

Verbruggen F, Logan GD (2008) Response inhibition in the stop-signal paradigm. Trends Cogn Sci 12:418-424. CrossRef Medline

Wen W, Zhu W, He Y, Kochan NA, Reppermund S, Slavin MJ, Brodaty H, Crawford J, Xia A, Sachdev P (2011) Discrete neuroanatomical networks are associated with specific cognitive abilities in old age. J Neurosci 31:1204-1212. CrossRef Medline

Wetheril GB, Chen H, Vasudeva RB (1966) Sequential estimation of quantal response curves - a new method of estimation. Biometrika 53:439-454.

White CN, Congdon E, Mumford JA, Karlsgodt KH, Sabb FW, Freimer NB, London ED, Cannon TD, Bilder RM, Poldrack RA (2014) Decomposing decision components in the stop-signal task: A model-based approach to individual differences in inhibitory control. J Cogn Neurosci 26:16011614. CrossRef Medline

Wilbertz T, Deserno L, Horstmann A, Neumann J, Villringer A, Heinze HJ, Boehler CN, Schlagenhauf F (2014) Response inhibition and its relation to multidimensional impulsivity. Neuroimage 103:241-248. CrossRef Medline

Wilson SM, Isenberg AL, Hickok G (2009) Neural correlates of word production stages delineated by parametric modulation of psycholinguistic variables. Hum Brain Mapp 30:3596-3608. CrossRef Medline

Winkler AD, Hu S, Li CS (2013) The influence of risky and conservative mental sets on cerebral activations of cognitive control. Int J Psychophysiol 287:254-261. CrossRef Medline

Yu AJ, Dayan P, Cohen JD (2009) Dynamics of attentional selection under conflict: Toward a rational Bayesian account. J Exp Psychol Human 35: 700-717. CrossRef

Zandbelt BB, Bloemendaal M, Neggers SF, Kahn RS, Vink M (2013) Expectations and violations: delineating the neural network of proactive inhibitory control. Hum Brain Mapp 34:2015-2024. CrossRef Medline

Zhang S, Tsai SJ, Hu S, Xu J, Chao HH, Calhoun VD, Li CS (2015) Independent component analysis of functional networks for response inhibition: Inter-subject variation in stop signal reaction time. Hum Brain Mapp 36:3289-3302. CrossRef Medline 